\title{
Multiculturalism or Revamped Monoculturalism: Exploring the Principles, Policies, and Practices Enacted in Korea's Changing Society
}

\author{
Josiah Gabriel Hunt \\ Adventist International Institute of Advanced Studies, United States \\ https://doi.org/10.47814/ijssrr.v3i4.53
}

\begin{abstract}
This theoretical essay critically explores the principles, policies, and practices enacted in South Korea under the banner "multiculturalism." The central finding advanced frames Korean multiculturalism as being a sociopolitical device that has the agenda of making migrants "multicultural" by understanding and adapting to Korean monoculturalism. The contribution of this study lies in its in-depth analysis of the rise of Korean multiculturalism in the years after the 1988 Seoul Olympic Games to the present time. The essay concludes with the recommendation that multicultural initiatives be designed to create a broader, more inclusive "we" that enhances Korea's national identity and culture.
\end{abstract}

Keyword: Korea; Multiculturalism; Monoculturalism; Society; Policy

\section{Introduction}

That Korea is a multicultural society is nothing new; however, its recognition and acceptance of itself as such is. For much of the 20th century, the myth of blood, ancestral, cultural, ethnic, and linguistic oneness was widely propagated among the Korean people (Ahn, 2013; Chung \& Kim, 2012; Hunt, 2017). Given the nation's history of colonization, division, and war, nationalism emphasizing a shared monoculture served as a cohesive ideology for development and national identity (Kang, 2010; Shim, Kim, \& Martin, 2008). The ushering in of the modern globalization age in the 1980 s, however, warranted adaption to an increasingly global economy (Landsman, Ham, \& Min, 2014; Shipper, 2012).

The deconstruction of national boundaries has, perforce, advanced the transnational flow of goods, information, peoples, practices, and values as never before (Hunt, 2014; Parrenas \& Kim, 2011). While a global phenomenon, unique to East Asian nations such as Japan, Korea, and Taiwan has been the polarity shift from being countries of emigration to countries of immigration (Kang, 2010; Kim \& Oh, 2011). Kong, Yoon, and $\mathrm{Yu}(2010)$ note that millions leave their homelands each year "to escape ... political repression, [obtain more favorable] economic opportunities, and/or join their families" abroad (p. 254). As the developmental period (1960-1988) furthered Korea's transformation into an economic powerhouse having the world's thirteenth largest economy (World Bank, 2015a), the number of migrants opting to make Korea "home" has significantly increased. 
Demographic statistics from the Ministry of Government Administration and Home Affairs (2015) show Korea as having a populace just over 51.32 million persons. While 1.74 million foreign residents comprise only $3.3 \%$ of the total population (Ministry of Government, 2015), "The annual average number of migrants in and out of Korea is 38,416,614" according to Oh et al. (2012) of the International Organization for Migration Research and Training Centre (p. 34). Thus, the conceptualized image of Korea as being a society homogenous in culture and language is a reality that is rapidly changing (J. Chung, 2011).

Within the last 2 decades, the sustained migration of foreign others has furthered Korea's transition from a homogenous to a heterogeneous multicultural, multiethnic society (Kang, 2010; Kim, Son, Jeong, \& Yoo, 2013). The steady arrival of migrant workers and marriage migrants from developing nations has altered the demographic composition of the nation (Hong \& Halvorsen, 2014; Jun, 2012). With the '88 Summer Olympic Games in Seoul as marking a turning point, the presence of foreign others - due to Korea's becoming a labor-importing nation (Chung \& Kim, 2012; G. Han, 2007) —is "erod[ing] the once-solid myth of South Korea's homogeneity, and with it, the taken for-granted assumption that South Korea is only for "Koreans" (Lim, 2010, p. 52). Accordingly, the Korean government's pronouncement that the nation is becoming a multicultural society in 2005 marked a noteworthy conceptual shift, as the ethnic basis for Korean nationalism became more civic and inclusive in nature (Kim \& Cho, 2015; N. Kim, 2014).

Before delving further into Korea's shift towards a multicultural society, it is essential to delineate the basic tenets of multiculturalism in order to better understand the nature of Korean multiculturalism. In contrast to ethnocentrism's viewing of one's "own cultural group as providing the norms for acceptable behavior and preferences" (Yoo, Jo, \& Jung, 2014, p. 91), multiculturalism is a type of recognition politics that acknowledges, accepts, respects, and supports the behavioral practices and unique identities of cultural groups (Ahn, 2012; N. Kim, 2014; Oh et al., 2012). As a term in and of itself, multiculturalism connotes the existence of cultural, linguistic, racial, social, and religious differences (N. Kim, 2014). Intercultural sensitivity is seen when these differences are positively recognized, accepted, and appreciated (Roh, 2014). Hence, the primary aim of multiculturalism is to deconstruct monoculturalism by protecting and preserving the rights and identities of raciocultural others.

The term for "multiculturalism" in Korean is Damunhwa (다문화). What is significant about the Korean term Damunhwa is that it emerged as a replacement for Honhyeol (혼혈; H. Kim, 2007; Jun, 2012) - a derogatory term meaning "mixed-blood" or "mixed-race" (Ahn, 2014; Gage, 2007; K. Han, 2007). In other words, the 20th century concept of Honhyeol, which was viewed as a threat to the ethnic purity of the nation (Ahn, 2013), is now lauded as Damunhwa in the 21st century. Hence, Kang's (2010) remark that Korea has transformed "into a 'mixed-blood[,]' multicultural society" (p. 287) reveals that mixed-blood (Honhyeol) and multicultural (Damunhwa) are in actuality one and the same. As the discussion that follows will soon make evident, Korean multiculturalism - its principles, policies, and educative approach — though having a multicultural appearance, is the right arm of Korean monoculturalism.

\section{A Changing Society}

So great has been the reversal of the emigrate-immigrate polarities that Oh et al. (2012) claim "the number of foreigners immigrating into Korea presently exceeds the number of Koreans migrating overseas" (p. 32). While immigrants leave their homelands for a variety of reasons, the burgeoning number of migrant workers coming to Korea in the late 1980s and early 1990s came to fill labor shortages in dirty, difficult, and dangerous (3D) jobs (Cheng, 2011; Kim \& Oh, 2011). 
The decade before the turn of the 21st century was a time in which Korea experienced labor shortages in the construction, fishery, garments, and manufacturing industries (i.e., 3D industries [Chung \& Kim, 2012; Jun, 2012]). While labor shortages are often attributable to a lack of manpower or skilled expertise, that experienced in Korea was the product of its increasingly educated populace's desire for higher income and their shunning of labor-intensive jobs (Choi, 2010; Kim \& Oh, 2011). The admission of immigrants, though once restricted to foreign investors and business professionals from developed nations (Kong et al., 2010), broadened in the 1990s to include migrant workers from developing nations "as replacements for the Korean workers who expect higher wages and better working conditions" (Hong \& Halvorsen, 2014, p. 254). This was in essence a win-win solution - as 3D job vacancies demanding cheap labor were filled by migrant workers desiring better pay (Kong et al., 2010). While an interest convergence exists between Koreans and migrants upon this point (for more on interest convergence, see Delgado \& Stefancic, 2012), their interests are essentially divergent — for while desiring to make Korea their permanent residence, migrants in 3D industries are required to return to their country of origin upon the completion of their contracts (renewable once), which the Employment Permit System grants for a maximum sojourn period of 3 years (J. Kim, 2011; N. Kim, 2014; Kong et al., 2010; Oh et al., 2012). Therefore, labor migrants are a solution - albeit a temporary one - to Korea's deficits in manpower in 3D industries that can be easily obtained, underpaid, and repatriated once their economic usefulness diminishes like "machine[s] without any attached human character" (N. Kim, 2014, p. 109).

While labor shortages in the early ' 90 s encouraged the practice of hiring foreign migrants, Korea's pending demographic crisis nurtured a shift away from the predominantly male-migrant model at the turn of the century (Ahn, 2012; Kim \& Cho, 2015). Demographically, Korea currently faces the challenges of an increasingly senior (aged) populace (Cheng, 2011), extremely low fertility rates (Jun, 2012; Lee, 2012; Oh et al., 2012), and an unbalanced male-female sex ratio (Lim, 2010). While all are of great concern, the latter two crises have contributed most to what Zlotnik (2003) terms the "feminization of international migration" (para. 4; see also Chung \& Kim, 2012; Kang, Callahan, \& Anne, 2015; Lee, 2012).

Korea's fertility rate has steadily declined over the last half century. While having an average fertility rate of 6.2 children per family in 1960, the rate thereafter plummeted to 4.53 in 1970, 2.6 in 1981, 1.6 in 1990, and to record low of 1.08 in 2005 (Cheng, 2011; Kim \& Oh, 2011; World Bank, 2015b). Not only is Korea's fertility rate the world's lowest, it is a rate that has since 1984 placed its populace below the replacement level (Cheng, 2011; Chung \& Kim, 2012). Oh et al. (2012) express concern about the population's forecasted decline from currently being 51.3 million to 42.3 million by 2050 . The state, declares Jun (2012), has sought to remedy its demographic crisis by investing in a Damunhwa population.

The traditional preference for sons in Korea's low fertility society has created an imbalance in the female-male sex ratio (Kang, 2010; Lee, 2012; Lim, 2010). While data from the Ministry of Government Administration and Home Affairs (2015) portray the 51.32 million registered resident population as being somewhat balanced with regard to gender (25.66 million males to 25.65 million females), numerous authors write of a shortage of marriageable women (see e.g., E. Chung, 2010; Chung \& Kim, 2012; Kim \& Oh, 2011; Lee, 2012; Lim, 2010; Parrenas \& Kim, 2011). This shortage not only exacerbates Korea's fertility problem, but has also resulted in a shift of emphasis from "productive" to "reproductive" migrants.

The Korean government has sought to alleviate its demographic crisis by means of gendered migration. Marriage migrants, "women who ... emigrate ... to developed countries to marry male citizens of those countries" (M. Kim, 2015, p. 103), are said to be the first "settler" immigrants in Korea (H. Kim, 2007, p. 101). Typically, marriage migrants marry Korean men who (a) live in rural areas, (b) have a low socio-economic status, (c) are in their late $30 \mathrm{~s}$ to $60 \mathrm{~s}$, (d) are widowed or divorced, or (e) have a 
disability (Cheng, 2011; Chung \& Kim, 2012; Jung, Yoo, \& Kim, 2014; Kang, 2010). Prior to 1996, international marriages brokered by provincial governments were predominantly between Korean men and Choson-jok (조선족 [ethnic Koreans from China]) due to their posing less of a threat to Korea's cultural identity (Lee, 2012; Lim, 2010).

With the opening of immigration policies in the years thereafter, vast numbers of marriage migrants hailing from China, Mongolia, the Philippines, Russia, Thailand, and Vietnam were sought out (Kim, Yoo, Jung, \& Yang, 2015; Kim et al., 2013). In contrast to their middle-aged spouses, women emigrating for the purpose of marriage range in age from their teens to late 20 s and generally have no more than a high school education (Kang et al., 2015; Kang, 2010). To such women, it is likely that marriage is viewed as a viable means of overcoming poverty, securing financial stability, and improving their quality of life.

H. Kim (2007) writes of a project initiated in the 1990s titled, "Getting Rural Bachelors Married" (p. 101). While this project title does not appear in any of the other literary works obtained, there is an undeniable emphasis placed upon rural bachelors and their marriage with foreign women from developing nations. In a sense, the Korean government's commodification of foreign women resulted in marriage migrants becoming "the most easily mobilized resource to solve" the demographic crisis (H. Kim, 2007, p. 106). That marriage between Koreans and raciocultural others producing "mixed-blood" was seen as a threat to national identity is now being celebrated as "Damunhwa" is anything but altruistic. One Catholic priest interviewed in E. Chung's (2010) study candidly remarked, "To the government, they [female marriage migrants] are simply baby-makers. When they can't fulfill their obligations or flee from their husbands, they become disposable, just like migrant workers"' (p. 695). M. Kim's (2015) assertion concurs with this notion: "Marriage migrant women represent a type of labor migrant between countries in that men seek spouses who require lower maintenance costs and are obedient" (p. 104). These women are "expected to be subservient, dutiful and (almost) wholly 'Korean' wives ... [,] unquestioningly grateful for the opportunity simply to live in a relatively wealthy country" (Lim, 2010, p. 67, emphasis added). It would then seem that the recent feminine gendering of migration, and its subsequent celebration as Damunhwa, has a hidden objective.

Data from Statistics Korea (2015) reveals approximately 364,500 marriages as having taken place between Koreans and foreign nationals from 2004 to 2014. Of this number 271,100 (74.3\%) were between Korea men and foreign women. The prevalence of Korean male-foreign female marriages can only be seen in its true importance in light of the 1946 Korean Nationality Act. Though later amended in 1998, the Korean Nationality Act restricted citizenship to those of patrilineal Korean descent, which in effect legally excluded all mixed-race individuals of matrilineal Korean descent (Ahn, 2013; Chung \& Kim, 2012). While constituting only $10.3 \%$ of the foreign population, the attention afforded to female marriage migrants through educational programs, multicultural policies, media coverage, social services, and scholarly literature suggests that Koreanness by patrilineal descent is still a prevalent, albeit unofficial, notion. Evidence of this is seen in the assertion that "foreign men, including migrant workers who are married to Korean women, are not supported by any service, including education" (H. Kim, 2007, p. 106). Hence, the literature points to Korean multiculturalism as not only gendered, but also assimilative.

The idea of "Koreanizing" female marriage migrants is critically discussed among few authors (see e.g., Kim \& Oh, 2011; Kim et al., 2013; Lim, 2010; Jung, Yoo, \& Kim, 2015). In describing the prevailing norms of Korean male-foreign female marriages, Lim (2010) writes that marriage migrants are not only required to follow their husband's culture, but to also forget their own. Kim and Oh (2011) also note, 
"foreign brides are expected to conform to the cultural norms of the host society, rather than the latter being expected to embrace multiculturalism" (p. 1565). Though the influx of migrant brides furthers the nation's evolution into a "multiethnic" society, Korea - as a family oriented society - has yet to become multicultural with regard to acknowledging, accepting, and supporting the cultural practices and identities of settler immigrants. Rather, as Cheng (2011) soberly observes, "By making Korean mothers out of migrant women, they reinstate the boundaries of the nation not by keeping out ethnically different women, but by disciplining them into a gendered sameness" (p. 1641). The maintenance of one's home culture instead of following their Korean husband's has led to some marriage migrants being described as having a "stubborn attitude" (Jung et al., 2015, p. 97) - a notion which may ultimately lead to them being rejected by their Korean relatives (Kim et al., 2013).

In a very real sense, Korea's demographic crisis finds resolution in the marriage migrant. Through the subsequent children they produce, these women are essentially a readily available means of obtaining much-needed social capital (M. Kim, 2015; Lee, 2012). However, this social capital comes at a price; namely, the dispelling of the national myth of ethnic homogeneity (Cheng, 2011). Nevertheless, the expectation of cultural assimilation-despite the existence of differences in language, religion, and worldview-remains unaltered (Lim, 2010). Mirroring Joseon Korea's willingness to help foreigners integrate into society (see K. Han, 2007; Hunt, 2017), so 21st century Korea welcomes marriage migrants and their families under the banner "Damunhwa," provided such individuals let go of their non-Korean ways.

The recent depiction of Korea as a "multicultural" society signifies a broadened understanding of nationhood that has within the 21 st century stretched to include multicultural families. Multicultural families have within the span of 27 years (1990-2017) redefined Korea to the extent that it can no longer putatively be considered a homogenous society. With the percentage of those considered multicultural increasing (Hong \& Halvorsen, 2014), the United Nations (2007) declared in the Report of the Committee on the Elimination of Racial Discrimination that viewing "Korea as an ethnically homogenous country . . no longer corresponds to the actual situation existing in the State" (p. 91). While the United Nations in the same report lambasts the use of the "pure-blood" and "mixed-blood" terms, they fail to realize its connection to Damunhwa. Furthermore, what is disconcerting about Korea being a multicultural society concerns how those who make it multicultural (i.e., families) are defined. For example, Kang (2010) defines a multicultural family as "one or both spouses composed of people of different ethnic or cultural backgrounds from monocultural Koreans" (p. 293); and Chung and Kim (2012) as "foreign spouses and their bicultural children" (p. 201). In both of these definitions the Korean spouse is absent, thus preserving his monocultural Korean identity. In discussing this, H. Kim (2007) writes, "The multicultural family is based on mono-cultural imagination" (p. 118). Korean multiculturalism's (a) favoring female migrants over male, (b) valuing "his" culture over "hers," (c) accepting Damunhwa children while historically rejecting Honhyeols (see Ahn, 2013), and (d) respective inclusion-exclusion of female marriage migrants and their Korean husbands in/from multicultural families reveals Damunhwa's paradoxical nature.

According to Kim Young-ok (as cited in Cheng, 2011), Korean multiculturalism is a form of "coercive assimilation rather than a recognition of difference" (p. 164). Some have said that multiculturalism was never a desired object, but rather the forced outcome of migrants and international brides settling in Korea (Ahn, 2012; Parrenas \& Kim, 2011). Indeed, previous discourse during the colonial and developmental years rendered migrant laborers, marriage migrants, and mixed-bloods as "others" excluded from Korean society (Cheng, 2011; Lim, 2010). The global age's transmigration of foreign nationals however (a) necessitated reconceptualizing Korean nationalism, and (b) ushered in an ideological 
shift from multiculturalism being a western challenge to a matter the Korean people must also face (Ahn, 2012; Jun, 2012). Writes Cheng (2011), “The claims of 'multiculturalism' reflect . . . the country's global ambition" (p. 1642).

While claiming to be a multicultural society with a foreign resident population of 1.74 million, Oh et al. (2012) note that if foreign ethnic Koreans are removed, Korea's foreign resident population - those staying for a period longer than 3 months - would plummet to 586,000 (i.e., 1.2\% of the total population). Furthermore, of the scores of foreigners who have migrated to Korea or become united through marriage to Koreans, fewer than 50,000 foreigners have ever obtained Korean nationality (Oh et al., 2012). While the presence of foreign others is on the rise, Korean multiculturalism may in truth be more of a perception than an actual reality.

\section{Perceptions and Policies}

The 2006 visit of Hines Ward, a biracial athlete honored as the Most Valuable Player in the National Football League's 2006 Super Bowl, was a watershed event triggering the positive reconceptualization of Korean society as being multicultural (Ahn, 2012; G. Han, 2007; K. Han, 2007; Kim \& Cho, 2015; Lim, 2010). "Hailed as a . . s symbol of what Korea might achieve if it [w]ould cease to call itself a single-raced nation" (K. Han, 2007, p. 9), multiculturalism thereafter became a catchphrase used to advance the notion of diversity as being a descriptor of the nation that should be embraced. According to Cho (2010) and Watson (2010), the conceptualization of a "Global Korea" denotes a new and inclusive approach to identity politics that casts the nation as being a transnational center for finance, information, and culture flows. That this has within the 21st century become an agenda pushed by the Korean government and mass media is significant, for as Ahn (2012) notes, Koreans have a "collective anxiety about . . . racially and ethnically different newcomers. . . [who] might influence, or even threaten, Korea['s] national identity . . . [as] a [']mono-ethnic['] nation" (p. 104). Hence as Ahn (2012) and Choi (2010) concurringly remark, the allimportant issue then becomes incorporating raciocultural others in such a way that balances diversity and unity without harming Korea's national identity.

While Korea's 20th century exclusive "us" nationalism led to the viewing of immigrants as populations to be "returned or expelled" rather than "incorporated" (E. Chung, 2010, p. 677), the shift towards a more inclusive nationalism in the 21 st century reified migrants' presence as "opportunities" for national growth and social development (Jun, 2012, p. 102). As an immigrant receiving country, the Korean government makes the most of such opportunities by determining who enters, their length of stay, and for what reasons (Lim, 2010). Pertaining to the previous statement, Kim and Oh (2011) describe the "who" as foreign laborers and marriage migrants; the term of stay as varying between contractual periods to permanent settlement (J. Kim, 2011; N. Kim, 2014); and the reason for admittance as needs- and assimilation-based, not diversity-based (Kong et al., 2010; Watson, 2010). While having the facade of furthering "an open, multicultural, and global society" (Ahn, 2013, p. 203), Jun (2012) writes of Korean multiculturalism as being "a disingenuous device used to govern and regulate different groups of migrants" (p. 104). This regulation is most evident in legislative policies and support systems furthering the assimilation of select groups in Korea's budding foreign population - namely, marriage migrants and Damunhwa children (see E. Chung, 2010).

That multicultural policies are believed to "define the present and future . . national strength of South Korea" (Watson, 2010, p. 337) posits the nation's strength as ultimately residing in marriage migrants. Though a debatable notion, of less controversy is the aim of Korea's multicultural policies. In Cheng's 
(2011) publication on citizenship and nationhood, multiculturalism is said to have become "the general banner under which the government promoted initiatives to assist marriage migrants and their families" ( $\mathrm{p}$. 1640, emphasis added). These initiatives are described in the literature as being gendered, assimilative, and focused on the social integration of female marriage migrants as a means of obtaining a multicultural society (see Chung \& Kim, 2012; Kang et al., 2015; Kim \& Oh, 2011; Watson, 2010). Rather than seeking to alter the mindset of the Korean majority population, the provisions made in the 2008 Support for Multicultural Families Act (Act No. 8937) further assimilation by providing Damunhwa families with Korean language training, counseling, and multicultural education courses (Kim et al., 2015; J. Kim, 2011; Lee, 2012). Cheng (2011) writes,

In spite of the language of multiculturalism, these services and proposals were designed to 'Koreanise' marriage migrants. In other words, migrants learn to be 'multicultural' by learning to be Korean, [furthering] ... the stability and authenticity of Korean families, culture[,] and society. (p. 1640)

What the above statement thus implies is that Korean multiculturalism is essentially migrants understanding, assimilating, and adapting to Korean monoculturalism. Should this observation prove to be true, the transformation of Korea into a multiethnic, multicultural society that yet espouses the ideological doctrine of oneness conditions the acceptance of foreign others upon the degree to which migrants adopt and adapt to the mores and values of Korean society (E. Chung, 2010; Jun, 2012). This in effect renders the focus of multicultural policies, programs, and practices not on the transformation of Korean society, but rather the assimilative integration of select groups into Korean society (Cheng, 2011; Chung \& Kim, 2012; J. Kim, 2011).

As the world becomes more diverse with each passing year, the need for multicultural education programs contextualized to Korea's rapidly changing society increases. In discussing the tenets of such programs, it is said that "multicultural education upholds the right to equal opportunity in education, affirms equity and full inclusion, calls for elimination of . . discrimination, urges respect for all cultures, and demands the guarantee of fundamental human dignity and universal human rights" (Kang, 2010, p. 288). While the Korean Ministry of Education and Human Resources recognizes the need for multicultural education (Kang, 2010), the programs and curricula their organization designs lack a necessary component (i.e., perspectives from multiple cultures). In actuality, writes Choi (2010), "multicultural education in South Korea is one-way cultural education" (p. 176). The fact that the multicultural education programs developed by the Korean Ministry of Education are designed almost exclusively to help "minority students" (Hong \& Halvorsen, 2014, p. 255) reveals an "underlying desire to lessen cultural disparity through assimilation and compartmentalization of diverse groups" (Schenck, 2013, p. 2). Furthermore, the primary objectives of the Education Act for Children in Multicultural Families is said to be to "teach children of multicultural families Korean culture, to help them learn Korean as well as their mother tongue, and to provide afterschool programs so that children ... who have a different cultural background adjust to Korean society" (Choi, 2010, p. 176). These programs place no demand upon Koreans to acquire multicultural perspectives, but are rather aimed at making foreigners "multicultural" by adopting the norms of Korean society. In effect, such educative programs reaffirm Korea's cultural identity, "rather than transforming the fabric of society to appreciate multicultural and linguistic differences" (Schenck, 2013, p. 2). As Hong and Halvorsen (2014) note, "Multicultural education is not just about 'them[,]' . . . [it] is also about 'us' because it requires critical reflection on how "we' make sense of 'them"' (p. 267). The viewing of immigrant populations as "opportunities" (Jun, 2012), "social capital" (M. Kim, 2015; Lee, 2012), and "cheap labor" (Kong et al., 2010) may then in effect further migrants' marginalization as commodities that can be expended or assimilated. 


\section{Conclusion}

Literature on multiculturalism essentially posits Korea's demographic change as being a product of (a) rapid industrialization during the developmental years, and (b) the arrival of the modern globalization age. Though once idealized as a nation-state homogenous in ancestry, blood, culture, and language (see e.g., Ahn, 2013; Hunt, 2017; Kang, 2010; Landsman et al., 2014; Oh et al., 2012; Seol, 2014; Shin, 2006), the presence of a growing foreign populace challenges the monolithic nature of Korean society (Choi, 2010). With the signal visit of Hines Ward in 2006, the belief in a monocultural and monoracial Korea gave way to the conceptualization of Korea as multicultural and multiethnic (N. Kim, 2014; Lim, 2010). Cheng (2011) writes, "The idea of multiculturalism allows the South Korean nation-state to assert its membership in the ranks of ethnically diverse and cosmopolitan global societies" (p. 1642); yet, as Watson (2010) points out, Korean multiculturalism was "driven by a sense of 'having to be' rather than 'wanting to be' multicultural" (p. 338). That Korean multiculturalism is essentially needs-based is evident in (a) immigration policies that restrict admission to select groups of migrants, and (b) immigrant policies that exploit and commodify migrants as a means of meeting economic and demographic challenges (see Jun, 2012; J. Kim, 2011; Kong et al., 2010; Oh et al., 2012).

One of the 21 st century challenges Korea faces as a multicultural society is maintaining national unity (Choi, 2010; Schenck, 2013). While unity in diversity refers to the harmonious coexistence of diverse cultural groups who maintain their unique identities while participating within a larger society (Baker, 1995), Korea's educational, political, and social stance mandates diversity in unity (i.e., unity in uniformity). Having "a national identity that implicitly, but unequivocally defines differences and diversity as undesirable and, therefore, inferior" (Lim, 2007, p. 4) presents an impasse for a nation that values advancement - for while desiring to remain a distinct people, global trends, foreign investment, and the importance of English as a lingua franca in business, education, and politics necessitate interaction with, and adaption to, an increasingly diverse and multicultural world.

Rather than treating migrants as populations to be taught, assimilated, and absorbed, future integration policies must strive to create a pluralistic, culture-friendly society where cultural diversity is not only periodically celebrated, but daily recognized and maintained in such a way that enhances Korea's shared national culture and identity. As N. Kim (2014) notes, this necessitates moving beyond "merely tolerating others" (p. 117) to embracing its multicultural population. This accordingly warrants a paradigm shift from seeking to change the few (i.e., migrants and their families) to altering the mindset of all (i.e., the Korean majority and migrant minority) as a means to create a broader more inclusive Korean "Uri" (우리 [we]). Whether viewed as migrants or settlers, immigrants are neither "threats" to be dealt with nor "opportunities" to be capitalized upon (see Jun, 2012; Lee, 2012; Lim, 2010); they are real persons with feelings, beliefs, values, and rich cultural and linguistic heritages. It is upon this premise that the sustained presence of raciocultural others demands a new conception of Korean oneness, multiculturalism, and nationhood in the 21 st century.

\section{References}

Ahn, J. (2012). Transforming Korea into a multicultural society: Reception of multicultural discourse and its discursive disposition in Korea. Asian Ethnicity, 13(1), 97-109. doi.10.1080/14631369.2012.625703 
Ahn, J. (2013). Visualizing race: Neoliberal multiculturalism and the struggle for Koreanness in contemporary South Korean television (Unpublished doctoral dissertation). Austin, Texas, The University of Texas at Austin.

Ahn, J. (2014). Rearticulating black mixed-race in the era of globalization: Hines Ward and the struggle for Koreanness in contemporary South Korean media. Cultural Studies, 28(3), 391417. doi:10.1080/09502386.2013.840665

Baker, D. (1995). Make us one: Celebrating spiritual unity in the midst of cultural diversity. Boise, ID: Pacific Press.

Cheng, S. (2011). Sexual protection, citizenship, and nationhood: Prostituted women and migrant wives in South Korea. Journal of Ethnic and Migration Studies, 37(10), 1627-1648. doi:10.1080/1369183X.2011.613335

Cho, M. (2010). Envisioning Seoul as a world city: The cultural politics of the Hong-dae cultural district. Asian Studies Review, 34, 329-347.

doi:10.1080/10357823.2010.508101

Choi, J. (2010). Educating citizens in a multicultural society: The case of South Korea. The Social Studies, 101, 174-178. doi:10.1080/00377990903284153

Chung, E. (2010). Workers or residents? Diverging patterns immigrant incorporation in Korea and Japan. Pacific Affairs, 83(4), 675-696.

Chung, J. (2011). The (dis)connection between policy and practice: Primary English education in South Korea (Doctoral dissertation). Retrieved from ProQuest Dissertations and Theses. (Accession Order No. 3484356)

Chung, E., \& Kim, D. (2012). Citizenship and marriage in a globalizing world: Multicultural families and monocultural nationality laws in Korea and Japan. Indiana Journal of Global Legal Studies, 19(1), 195-219.

Delgado, R., \& Stefancic, J. (2012). Critical race theory: An introduction (2nd ed.). New York, NY: New York University Press.

Gage, S. (2007). Pure mixed blood: The multiple identities of Ameriasians in South Korea (Doctoral dissertation). Retrieved from ProQuest Dissertations and Theses. (Accession Order No. 3253643)

Han, G. (2007). Multicultural Korea: Celebration or challenge of multiethnic shift in contemporary Korea? Korea Journal, 47(4), 32-63. Retrieved from https://www.ekoreajournal.net/issue/index $2 . h t m ? I d x=419$ 
Han, K. (2007). The archeology of the ethnically homogenous nation-state and multiculturalism in Korea. Korea Journal, 47(4), 8-31. Retrieved from https://www.ekoreajournal.net/issue/index2.htm?Idx=419\#

Hong, W., \& Halvorsen, A. (2014). Teaching the USA in South Korean secondary classrooms: The curriculum of 'the superior other.' J. Curriculum Studies, 46(2), 249-275. doi:10.1080/00220272.2013.777122

Hunt, J. (2014). From western English to global English: Issues in cultural and pragmatic instruction. American Journal of Educational Research, 2(12C), 4-7. doi:10.12691/education-2-12C-2

Hunt, J. (2017). A nation of one: A critical analysis of the rise of the notion of ethnocultural oneness in twentieth-century Korea. Manuscript submitted for publication.

Jun, E. (2012). We have to transform ourselves first: The ethics of liberal developmentalism and multicultural governance in South Korea. Focaal: Journal of Global and Historical Anthropology, 64, 99-112. doi:10.3167/fcl.2012.640109

Jung, E., Yoo, E., \& Kim, H. (2014). Life experience of married immigrant women in Korea. Advanced Science and Technology Letters: Healthcare and Nursing, 61, 85-88. doi:10.14257/astl.2014.61.21

Jung, E., Yoo, E., Kim, H. (2015). Life experience of Korean men who married immigrant women in Korea. Advanced Science and Technology Letters: IRTT, 96, 95-98. doi:10.14257/ast1.2015.96.20

Kang, H., Callahan, J., \& Anne, M. (2015). An intersectional social capital model of career development for international marriage immigrants. The Career Development Quarterly, 63, 238-252. doi:10.1002/cdq.12016

Kang, S. (2010). Multicultural education and the rights to education of migrant children in South Korea. Educational Review, 62(3), 287-300. doi:10.1080/00131911.2010.503599

Kim, H. J., Yoo, E., Jung, E., \& Yang, M. (2015). Spiritual well-being of foreign immigrant women married to Korean men. Advanced Science and Technology Letters: Healthcare and Nursing, 88, 154-157. doi:10.14257/astl.2015.88.32

Kim, H. M. (2007). The state and migrant women: Diverging hopes in the making of multicultural families in contemporary Korea. Korea Journal, 47(4), 100-122. 
Kim, H. M., \& Cho, C. (2015). Comparative analysis of multi-cultural situations between Germany and Korea-Focusing on multicultural backgrounds, characteristics and policies for social integration. Advanced Science and Technology Letters: Art, Culture, Game, Graphics, Broadcasting and Digital Contents, 87, 100-107. doi:10.14257/astl.2015.87.21

Kim, H. R., \& Oh, I. (2011). Migration and multicultural contention in East Asia. Journal of Ethnic and Migration Studies, 37(10), 1563-1581. doi:10.1080/1369183X.2011.613332

Kim, J. (2011). The politics of culture in multicultural Korea. The Journal of Ethnic and Migration Studies, $37(10)$,

1583-1604. doi:10.1080/1369183X.2011.613333

Kim, M. (2015). The Korean government's recent response to address issues surrounding marriage migrants. Advanced Science and Technology Letters, 91, 103-108. doi:10.14257/ast1.2015.91.22

Kim, N. (2014). Multicultural challenges in Korea: The current stage and prospect. International Migration, $52(2)$ 100-121. doi:10.1111/j.1468-2435.2009.00582.x

Kim, Y. M., Son, M., Jeong, S., \& Yoo, E. (2013). Cultural transition and well-being experience of immigrant women married to Korean men in South Korea. Advanced Science and Technology Letters: Healthcare and Nursing, 40, 19-23. doi:10.14257/ast1.2013.40.05

Kong, D., Yoon, K., \& Yu, S. (2010). The social dimensions of immigration in Korea. Journal of Contemporary Asia, $40(2)$ 252-274. doi:10.1080/00472331003600473

Landsman, G., Ham, J., \& Min, H. (2014). Multiculturalism in Korea and differing views of adaption based on foreign interaction with Korean culture. Advanced Science and Technology Letters, 71, 145-148. Retrieved from http://onlinepresent.org/proceedings/vol71_2014/34.pdf

Lee, H. O. (2012). Political economy of cross-border marriage: Economic development and social reproduction in Korea. Feminists Economics, 18(2), 177-200. doi:10.1080/13545701.2012.688139

Ministry of Government Administration and Home Affairs. (2015). Statistical yearbook. Retrieved from www.korea.kr/common/download.do?tblKey $=$ EDN\&fileId $=210513$

Oh, J., Kang, D., Shin, J., Lee, S. L., Lee, S. B., \& Chung, K. (2012). Migration profile of the Republic of Korea. Retrieved from http://publications.iom.int /bookstore/free/MP_Korea.pdf 
Parrenas, R., \& Kim, J. (2011). Multicultural East Asia: An introduction. Journal of Ethnic and Migration Studies, doi:10.1080/1369183X.2011.613331

$37(10)$,

1555-1561.

Roh, S. (2014). A study on the factors affecting the intercultural sensitivity of middle and high school students in Korea. Advanced Science and Technology Letters: Education, 47, 266269. doi:10.14257/ast1.2014.47.61

Schenck, A. (2013). Korea's “model minority": A case study of an American-Korean bilingual student's challenges learning English in South Korea. Journal of International Education and Leadership, 3(3), 1-15.

Seol, D. (2014). The citizenship of foreign workers: Stratified formation, fragmented evolution. In K. Chang (Ed.), South Korea in transition: Politics and culture of citizenship (pp. 131-145). New York, NY: Routledge.

Shim, T., Kim, M. S., \& Martin, J. (2008). Changing Korea: Understanding culture and communication. New York, NY: Peter Lang.

Shin, G. (2006). Ethnic nationalism in Korea. Stanford, CA: Stanford University Press.

Shipper, A. (2012). Influence of the weak: The role of foreigners, activism, and NGO networks in democratizing Northeast Asia. International Studies Quarterly, 56, 689-703. doi: $10.1111 / \mathrm{j} .1468-2478.2012 .00742 . \mathrm{x}$

Statistics Korea. (2015, April 23). Marriage and divorce statistics in 2014. Retrieved from http://kostat.go.kr/portal/english/news/1/1/index.board

United Nations. (2007). Report of the committee on the elimination of racial discrimination. New York, NY: United Nations.

Watson, I. (2010). Multiculturalism in South Korea: A critical assessment. Journal of Contemporary Asia, 40(2), 337-346. doi:10.1080/00472331003600549

World Bank. (2015a). Fertility rate, total (births per woman). Retrieved from http://data.worldbank.org/indicator/SP.DYN.TFRT.IN/countries/1W?page=6\&display=de fault

World Bank. (2015b). Gross domestic product 2013, PPP. Retrieved from http://databank.worldbank.org/data/download/GDP_PPP.pdf

Yoo, J. W., Jo, S. S., \& Jung, J. M. (2014). The effects of television viewing, cultural proximity, and ethnocentrism on country image. Social Behavior and Personality, 42(1), 89-96. doi:10.2224/sbp.2014.42.1.89 
Zlotnik, H. (2003). The global dimensions of female migration. Retrieved from http://www.migrationpolicy.org/article/global-dimensions-female-migration

\section{Copyrights}

Copyright for this article is retained by the author(s), with first publication rights granted to the journal.

This is an open-access article distributed under the terms and conditions of the Creative Commons Attribution license (http://creativecommons.org/licenses/by/4.0/). 